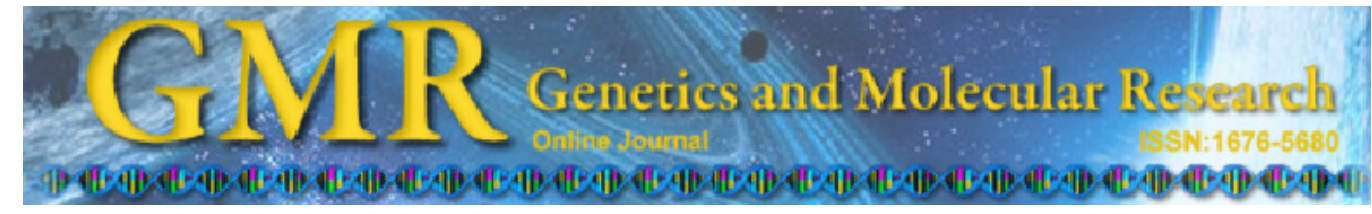

Case Report

\title{
New cytogenetic aberrations found in a case of aggressive retinoblastoma
}

\author{
J.E.X.S. Barros ${ }^{1,2}$, E.M. Soares-Ventura ${ }^{1}$, N. Santos ${ }^{2}$, B.A.S. Amaral ${ }^{1,2}$, \\ F.M. Oliveira ${ }^{4}$, R.S. Vera Cruz ${ }^{1}$, V.L.L. Morais ${ }^{1}$, T.J. Marques-Salles ${ }^{1,2}$ \\ and M.T.C. Muniz ${ }^{1,3}$ \\ ${ }^{1}$ Centro de Oncohematologia Pediátrica, Hospital Universitário Oswaldo Cruz, \\ Universidade de Pernambuco, Recife, PE, Brasil \\ ${ }^{2}$ Departamento de Genética, Universidade Federal de Pernambuco, \\ Recife, PE, Brasil \\ ${ }^{3}$ Faculdade de Ciências Médicas, Universidade de Pernambuco, \\ Recife, PE, Brasil \\ ${ }^{4}$ Departamento de Clínica Médica, \\ Instituto Nacional de Ciência e Tecnologia em Células-Tronco e Terapia Celular, \\ Universidade de São Paulo, Ribeirão Preto, SP, Brasil
}

Corresponding author: J.E.X.S. Barros

E-mail: jemimaeline@gmail.com

Genet. Mol. Res. 11 (2): 1666-1670 (2012)

Received October 24, 2011

Accepted January 19, 2012

Published June 15, 2012

DOI http://dx.doi.org/10.4238/2012.June.15.16

ABSTRACT. We describe a case of retinoblastoma with an atypical
presentation and previously unreported cytogenetic aberrations. A
19-month-old girl with left intraocular retinoblastoma was treated
with enucleation and chemotherapy. The disease showed aggressive
evolution within a short period between diagnosis and relapse. Eight
months after diagnosis, a new large tumor was present in the orbit of the
right eye, with diffuse bone pain, pancytopenia and diffuse infiltration
into the bone marrow and the central nervous system. The child did
not respond to treatment and died. Cytogenetic studies made with
G-banding, FISH and SKY analysis showed chromosomal aberrations
commonly associated with retinoblastoma, including del(13q), i(6p), 
+1 , and monosomy 16 , along with others that had not been reported previously, including $\operatorname{dup}(5 q)$, dic $(15 ; 22)$ and $\operatorname{add}(14 q)$. The new chromosomal aberrations may be related to the aggressiveness of the disease in this case.

Key words: Retinoblastoma; Cytogenetics; del(13q); i(6p)

\section{INTRODUCTION}

Retinoblastoma $(\mathrm{Rb})$ is the most common intraocular malignancy in childhood, with an annual incidence of 1/15,000-20,000 live births (Aerts et al., 2006). It can be unifocal or multifocal, affecting one or both eyes at the same time, and it is termed sporadic or hereditary. It requires complex treatment, encompassing several therapeutic strategies in order to preserve life and eyesight (Erwenne et al., 2003).

$\mathrm{Rb}$ can infiltrate the brain via the optic nerve or the adjacent tissues, and thus, the disease can become extraocular (Chintagumpala et al., 2007). Metastatic disease with no evidence of optic nerve involvement is rare. Lumbar puncture with cerebrospinal fluid analysis and bone marrow aspiration are not routinely performed. However, these tests are indicated in children with advanced intraocular disease or with evidence of extraocular disease at presentation (Melamud et al., 2006). Rb can disseminate to other parts of the body including the bone marrow, although this rarely occurs, and it is generally scattered among normal elements (Khurshid et al., 2004). Some tumors such as neuroblastoma and medulloblastoma can fully infiltrate the bone marrow and thus simulate acute leukemia (Inoue et al., 1974). Nevertheless, when this pattern of disease occurs, it provides us the opportunity to examine directly the karyotype of the tumor cells. The specific cytogenetic abnormalities may also be of value in suggesting the diagnosis of the disease (Daly et al., 1987; Oliveros and Yunis, 1995).

The present study describes an atypical case of a child with left intraocular $\mathrm{Rb}$ at diagnosis who was treated with enucleation prior to chemotherapy. However, eight months after diagnosis, a large tumor was present in the right orbit, along with diffuse bone pain, pancytopenia and diffuse infiltration into bone marrow and into the CNS. Cytogenetic analysis of bone marrow cells showed chromosomal aberrations common to Rb, such as del(13q), i( $6 \mathrm{p}),+1$, and monosomy 16 , besides others not yet described, including $\operatorname{dup}(5 q), \operatorname{dic}(15 ; 22)$ and $\operatorname{add}(14 q)$.

\section{CASE REPORT}

A 19-month-old girl was admitted to our institution with leukocoria in the left eye in December 2003. Retina mapping showed a vascularized, white-mass tumor with points of calcification, occupying more than half of the retina and making it difficult to see the optic nerve. There was vitreous hemorrhage associated with endophytic and exophytic growth. Cranial computed tomography and magnetic resonance imaging revealed a localized left eye tumor. A histopathological study revealed an $\mathrm{Rb}$ that had surrounded the head of the optic nerve, but not beyond the lamina cribosa (Group V, Reese-Ellsworth classification) (Linn, 2005). Laboratory tests, cerebrospinal fluid (CSF) and bone marrow showed no abnormalities.

The patient was treated with enucleation and chemotherapy in accordance with a Brazilian Retinoblastoma Protocol (Antonelli et al., 2003). The treatment was completed in May 
2004, and she was followed up monthly. Four months after the end of the treatment, she was hospitalized with leg pain, lethargy, irritability, and a hardened tumor in the orbit of the right eye. A complete blood count revealed a low platelet count $\left(49,000 / \mathrm{mm}^{3}\right)$, and biochemical tests showed high levels of LDH (1033 IU). Cerebral tomography showed an extensive extra axial mass surrounding the frontal region. Anatomopathological examination of the tumor in the right orbit revealed the presence of malignant small-cell neoplasia and immunohistochemical tests were positive for S100 protein, synaptophysin, NSF, and GFAP, and negative for CD99 and NB84. Bone marrow showed a massive malignant infiltration of small round cells, with scarce and basophilic cytoplasm and few visible nucleoli. Immunophenotypic tests of tumors cells were negative for leukemia markers. Cytogenetic analysis by the G-banding disclosed the following: 47,XX,+1, dup(5)(q11.2;q35),+i(6p), del(13)(q12;q14), add(14)(q32), dic(15;22)(p11.1;q13), $-16,+\operatorname{mar}[10] / 47, \mathrm{XX},+1, \operatorname{dup}(5)(\mathrm{q} 11.2 ; \mathrm{q} 35),+\mathrm{i}(6 \mathrm{p}), \operatorname{del}(13)(\mathrm{q} 12 ; \mathrm{q} 14), \operatorname{add}(14)(\mathrm{q} 32), \operatorname{dic}(15 ; 22)$ (p11.1;q13)[5]/48,XX,+1,dup(5)(q11.2;q35), +i(6p), del(13)(q12;q14), add(14)(q32), dic(15;22) (p11.1;q13), + mar[1] (Figure 1A). Fluorescent in situ hybridization (FISH) using a $6 \mathrm{p}$ probe (QBiogene) showed three signals: two normal 6p and one i $(6 p)$ in the five metaphases analyzed (Figure 1B). SKY analysis confirmed the abnormalities previously seen by G-banding and identified the origin of the marker chromosome as chromosome 1 (Figure 1C). The definitive karyotype found was $48, \mathrm{XX},+1,+1 \operatorname{dup}(5)(\mathrm{q} 11.2 ; \mathrm{q} 35),+\mathrm{i}(6 \mathrm{p}), \operatorname{del}(13)(\mathrm{q} 12 ; \mathrm{q} 14), \operatorname{add}(14)(\mathrm{q} 32), \operatorname{dic}(15 ; 22)$ (p11.1;q13),-16. RT-PCR analysis did not detect $\mathrm{t}(4,11), \mathrm{t}(1,19), \mathrm{t}(9,22), \mathrm{t}(12,21), \mathrm{t}(11 ; 22)$ or amplifications of the $M Y C N$ gene in tumor cells or bone marrow.
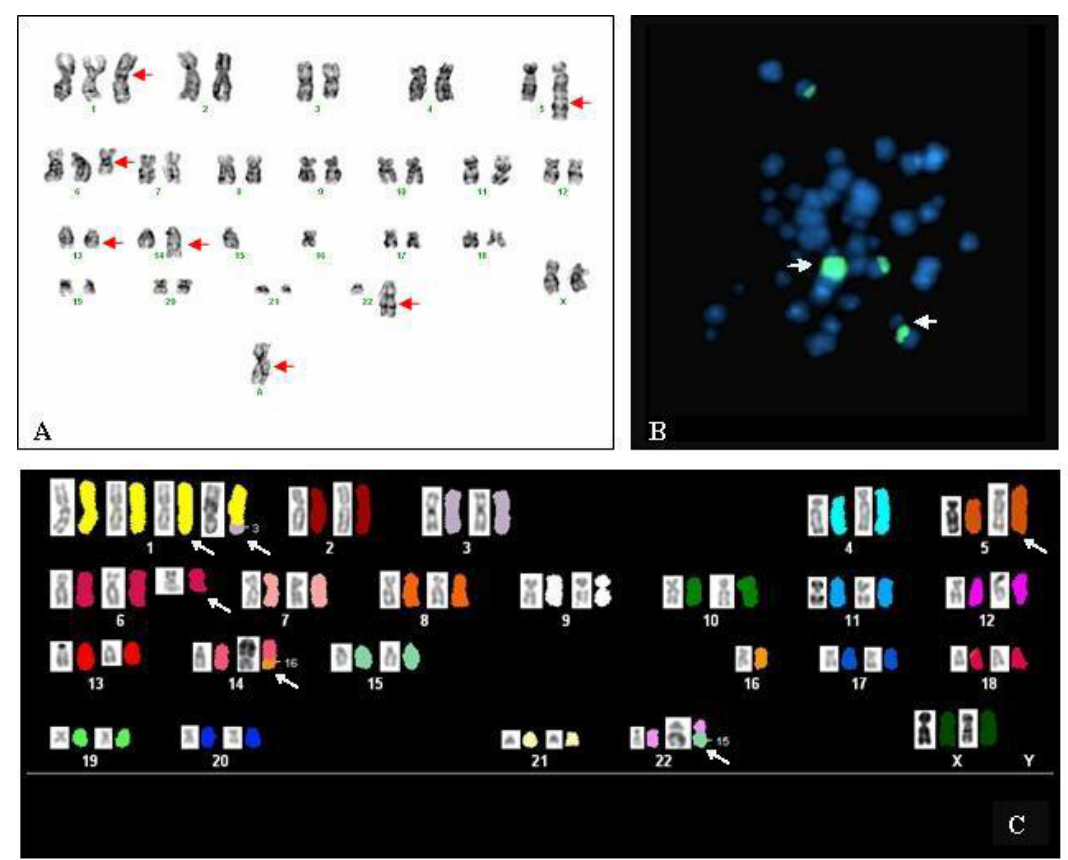

Figure 1. G-banding, FISH and SKY analysis of the patient. A. G-banded karyotype: 47,XX,+1,dup(5)(q11.2;q35),+i(6) (p10), del(13)(q12;q14), add(14)(q32), dic(15;22)(p11.1;q13),-16,+mar[10]. B. FISH using 6p probe. Arrow indicates i(6p). C. SKY karyotype showing the inverted DAPI (left) and the classified (right) profiles for each chromosome. Extra copies of chromosome 1, where one of them has insertion of part of chromosome 3, ins(1;3)(q21;q26q29), dup (5) $(\mathrm{q} 11.2 ; \mathrm{q} 35),+\mathrm{i}(6)(\mathrm{p} 10), \operatorname{del}(13)(\mathrm{q} 12 ; \mathrm{q} 14), \mathrm{t}(14 ; 16)(\mathrm{q} 32 ; \mathrm{q} 11.1), \operatorname{dic}(15 ; 22)(\mathrm{p} 11.1 ; \mathrm{q} 13$, were indicated by arrows. 
The child was treated for relapse with ifosfamide, carboplatin and etoposide. In February 2005, the child presented seizures and malignant cells infiltrating the spinal fluid. A new treatment was tried with carboplatin, vincristine and intrathecal chemotherapy, followed by cranial and neuraxial radiotherapy. In May 2005, the patient no longer responded to chemotherapy and died of progressive disease.

\section{DISCUSSION}

Since 1993, $125 \mathrm{Rb}$ cases have been registered in our institution, but only one with bone marrow totally infiltrated by immature cells. Three similar cases have already been described in the literature and the diagnoses were based on histopathological and cytogenetic studies (Inoue et al., 1974; Daly et al., 1987; Khurshid et al., 2004). The main cytogenetic alterations described in $\mathrm{Rb}$ are del(13), gain $1 \mathrm{q}$ and $6 \mathrm{p}$, loss of $5 \mathrm{q}$, and monosomy 16 . Because few cases of Rb diffusely infiltrating in the bone marrow had been described, it is very difficult to know which cytogenetic alterations are involved and its relation to aggressiveness of disease.

The deletion of $13 q$ is the alteration directly responsible for $\mathrm{Rb}$, where the tumor suppressor gene $R B 1$ is located, also $\mathrm{i}(6 \mathrm{p})$ is important since it is the most common abnormality found in 50 to $60 \%$ of $\mathrm{Rb}$ cases. The presence of $\mathrm{i}(6 \mathrm{p})$ may be an important genetic change in the development and progression of the tumor (Paderova et al., 2007). Other regions such as 1q36 (E2F2 and ID3), 2p24-25 (ID2 and MYCN), 9p (p16), and 16p22 (E2F4) are also involved in the $\mathrm{pRb}$ pathway. Perhaps these regions contribute towards a third event that is necessary for completing the malignant transformation (Mairal et al., 2000; Chen et al., 2001). The new cytogenetic abnormalities described in this case were duplication 5q, add(14q) and $\operatorname{dic}(15 ; 22)$. It is possible that these changes played a role in the dissemination and progression of disease.

The atypical bilateral $\mathrm{Rb}$ case described here had an aggressive evolution with short period between diagnosis and relapse. The tumor cells did not respond to chemotherapy and the child died shortly afterwards. Certainly, the cytogenetic studies helped to diagnose the disease, but other cases of disseminated $\mathrm{Rb}$ need to be studied to clarify when cytogenetic abnormalities are present and to know whether they are present at the beginning of the disease, as well as determining their importance in the evolution of the disease.

\section{ACKNOWLEDGMENTS}

Research supported by Banco do Brasil Foundation through Criança e Vida Project, Fundação de Amparo à Ciência e Tecnologia do Estado de Pernambuco (FACEPE) and Coordenação de Aperfeiçoamento de Pessoal de Nível Superior (CAPES).

\section{REFERENCES}

Aerts I, Lumbroso-Le RL, Gauthier-Villars M, Brisse H, et al. (2006). Retinoblastoma. Orphanet J. Rare Dis. 1: 31.

Antonelli CBG, Steinhorst F, Ribeiro KCB and Erwenne CM (2003). Evolução da terapêutica do retinoblastoma. Arq. Bras. Oftalmol. 66: 401-408.

Chen D, Gallie BL and Squire JA (2001). Minimal regions of chromosomal imbalance in retinoblastoma detected by comparative genomic hybridization. Cancer Genet. Cytogenet. 129: 57-63.

Chintagumpala M, Chevez-Barrios P, Paysse EA, Plon SE, et al. (2007). Retinoblastoma: review of current management. Oncologist 12: 1237-1246.

Daly HA, Davison EV, Pearson AD, Reid MM, et al. (1987). Chromosomes of metastatic retinoblastoma. Arch. Dis. Child 
62: 410-411.

Erwenne CM, Antonelli CBG, Marback EF and Novaes PE (2003). Tratamento conservador em retinoblastoma intraocular. Arq. Bras. Oftalmol. 66: 791-795.

Inoue S, Ravindranath Y, Ottenbreit MJ, Thompson RI, et al. (1974). Chromosomal analysis of metastatic retinoblastoma cells. Humangenetik 25: 111-118.

Khurshid I, Naeem S, Bashir F and Lone A (2004). Retinoblastoma; Bone marrow infiltration - A study of 30 cases. Ann. King Edwar. Med. Coll. 10: 194-196.

Linn MA (2005). Intraocular retinoblastoma: the case for a new group classification. Ophthalmol. Clin. North Am. 18 41-53, viii.

Mairal A, Pinglier E, Gilbert E, Peter M, et al. (2000). Detection of chromosome imbalances in retinoblastoma by parallel karyotype and CGH analyses. Genes Chromosomes Cancer 28: 370-379.

Melamud A, Palekar R and Singh A (2006). Retinoblastoma. Am. Fam. Physician 73: 1039-1044.

Oliveros O and Yunis E (1995). Chromosome evolution in retinoblastoma. Cancer Genet. Cytogenet. 82: 155-160.

Paderova J, Orlic-Milacic M, Yoshimoto M, da Cunha SG, et al. (2007). Novel 6p rearrangements and recurrent translocation breakpoints in retinoblastoma cell lines identified by spectral karyotyping and mBAND analyses. Cancer Genet. Cytogenet. 179: 102-111. 